\title{
O conceito de 'poder' - comparando a proposta clássica de Steven Lukes e seu uso na ciência política com a sociologia de Pierre Bourdieu
}

\author{
Maria Thereza Macedo Pedroso ${ }^{1}$
}

\section{Resumo}

Este artigo pretende comparar um conceito-chave que é típico das Ciências Sociais, embora mais discutido e analisado na Ciência Política - o conceito de poder. Apresenta-se a visão tridimensional do poder, originalmente proposta por Steven Lukes, em 1974. A comparação é com uma formulação tipicamente sociológica, a teoria cultural do poder proposta por Pierre Bourdieu e resultante da vasta produção científica do autor francês. As contribuições dos dois autores são apresentadas sucintamente em duas seções, e uma terceira seção analisa comparativamente o alcance interpretativo dos conceitos de poder em ambos os autores.

Palavras-chave: Poder. Visão tridimensional do poder. Teorias do poder de Lukes e de Bourdieu. Cubo do poder

\section{Abstract}

The main objective of the article is to compare a key concept that is typical of Social Sciences, though more discussed and analyzed in Political Science - the concept of power. It is presented the tridimensional view of power originally proposed by Steven Lukes in 1974. A comparison is made with a framework typically sociological, the cultural theory of power proposed by Pierre Bourdieu that resulted from the vast scientific production of the French author. The contributions of the two authors are succinctly presented in two sections and a third section comparatively analyses the interpretative scope of the concept of power submitted by both authors.

Keywords: Power. Tridimensional view of power. Theory of power proposed by Pierre and Bourdieu. Power Cubo.

\footnotetext{
${ }_{1}^{1}$ Pesquisadora da Embrapa, doutoranda do CEPPAC/UnB. Maria.Pedroso@embrapa.br 


\title{
1 Introdução
}

\begin{abstract}
[...] So that in the first place, I put for a generall inclination of all mankind, a perpetuall and restlesse desire of Power after power, that ceaseth onely in Death.And the cause of this is not alwayes that a man hopes for a more intensive delight, than he has already attainedto; or that he cannot be content with a moderatepower: but because he cannot assure the power andmeans to live well, which he hath present, without theacquisition of more (HOBBES, 1909, p. 75, grifo nosso).
\end{abstract}

Em um livro recentemente publicado, que discute a desigualdade social, um dos maiores especialistas em "distribuição de renda", o economista Branko Milanovic, também um dos principais economistas do Banco Mundial (e, portanto, com acesso a bancos de informação empírica e estatística que estão entre os mais completos e sofisticados) escreveu que "[...] a desigualdade apareceu assim que nasceu a sociedade humana, porque as distinções em poder e riqueza acompanham todas as sociedades humanas" (MILANOVIC, 2012, p. 11). A curta citação é apropriada, porque permite introduzir este artigo, reiterando pelo menos dois aspectos cruciais relativos ao tema que será tratado nas páginas seguintes. Primeiramente, que o poder acompanha todas as sociedades humanas. Ou seja, afirmado mais simplesmente, significa que, à medida que surgiram os coletivos sociais, nasceram igualmente (e imediatamente) as hierarquias sociais e seus correlatos mais próximos: a dominação, a autoridade (de todos os tipos). Para tanto, exigiu-se disciplina e obediência, quando não a aberta subalternidade - enfim, o poder. Os humanos, nascidos iguais entre si, logo se tornaram desiguais por força de diversos mecanismos, quase todos desenvolvidos pelos próprios indivíduos (ou seja, mecanismos principalmente sociais), basicamente com um único e exclusivo objetivo: distribuir desigualmente o poder entre aquelas coletividades sociais, que foram sendo formadas ao longo dos tempos e, assim, desenvolver sociedades marcadas por assimetrias sociais.

Em segundo lugar, a breve citação também permite associar intimamente o fenômeno da desigualdade aos seus dois vetores principais: a apropriação do poder (usualmente o poder político) e a igual apropriação da riqueza. Ou seja, um fenômeno social, quase sempre tornado político em todas as sociedades humanas (a distribuição do poder), está associado, quase inevitavelmente, a uma correspondente (e desigual) 
distribuição dos bens materiais, ou, mais genericamente, à riqueza em geral. Em síntese: as manifestações de poder, que no geral são sociais e políticas, normalmente têm uma necessária face econômica (seria o "poder econômico"). Na história do pensamento social, esse seria um infindável debate: $O$ que origina o quê? O poder econômico ou o poder político?

O presente artigo, no entanto, concentra-se na esfera mais restrita do poder político e não discutirá, senão indiretamente, o poder econômico. Também não tenta responder à pergunta acima, inspiradora de renovados debates nas Ciências Sociais, sobretudo entre os defensores dos enfoques marxistas e estruturalistas.

Portanto, é provável que o termo "poder" seja um dos mais utilizados pelos indivíduos de uma dada comunidade social, ou na própria sociedade mais ampla. Normalmente, significa algo vagamente definido, mas intuído pela maioria, embora sem enfocar diretamente o seu conteúdo conceitual. Usualmente, também o que é afirmado sobre o poder se refere muito mais aos seus efeitos práticos, em decorrência do seu exercício por alguém ou por um grupo de pessoas, e indicaria uma "capacidade" de um agente social. Mais raramente, o foco incide sobre a sua natureza, significado e consequências. Dessa forma, conforme a epígrafe hobbesiana, se é uma evidência histórica que o "poder" seria a principal e geral "inclinação" da existência humana, um "perpétuo e incansável desejo", na referência hobbesiana acima, como seria então definido e, em especial, como se utiliza o poder?

Não obstantes diversas referências, diretas e indiretas, encontradas em autores do passado (incluindo os pensadores da Grécia antiga), nas Ciências Sociais, é provável que o ponto de partida mais explícito e conceitual seja aquele proposto por Weber, um dos autores fundadores das "ciências do homem" (como assim se chamava então na Alemanha) e que se dedicou diretamente ao estudo do poder e de suas características principais. Além disso, também analisou a relação entre o poder e os fenômenos sociais e políticos a ele associados. Para Weber, em tradução mais livre, "Poder significa toda a probabilidade de, dentro de uma relação social, impor a vontade própria mesmo contra a resistência, seja qual for o fundamento dessa probabilidade" (WEBER, 2012, p. 84). Esse entendimento, proposto pelo autor alemão nas primeiras 
décadas do século passado, entrou na teoria social a partir de 1922, fixou-se quando diversos de seus escritos foram reunidos em seu livro mais erudito "Economia e sociedade".

Alinhando-se parcialmente com esta trajetória intelectual, um cientista social, Steven Lukes, publicou, em 1974, um pequeno livro intitulado "Power. A radical view" (Londres: Macmillan), no qual avançou substancialmente, a partir da definição weberiana, e seu livro se tornou rapidamente um clássico e estudo referencial, sobretudo, para os autores da Ciência Política. Desde então, toda e qualquer discussão sobre poder tem sido decorrência da proposta analítica de Lukes, seja aceitando-a, ou, então, aperfeiçoando-a.

Entre janeiro de 1975 e junho de 2006, por exemplo, pouco mais de 1,2 mil artigos no campo da Ciência Política usaram a formulação teórica de Lukes para discutir o conceito de poder, ou aplicá-lo em estudos empíricos (BÉLAND, 2006).

Três décadas depois, o autor publicou uma segunda edição "revisitada", na qual praticamente reproduziu (com pequenas alterações) a versão original dos anos setenta, mas adicionou dois capítulos novos. O primeiro deles discute as críticas recebidas ao seu primeiro livro, enquanto o outro capítulo adicionado discute criativamente dois autores que também analisaram (após a primeira edição de 1974) o poder e suas manifestações, Foucault e Bourdieu (LUKES, 2005). Infelizmente, nenhum dos dois livros de Lukes tem ainda uma versão em português.

O presente artigo apresenta, em sua primeira seção, uma síntese dos argumentos de Lukes sobre poder, enfatizando a sua "visão tri-dimensional" sobre as manifestações de poder na sociedade. Dessa forma, esta primeira parte discute um conceito que tem sido, desde então, mais fortemente influente no campo da Ciência Política, ainda que utilizado também por analistas de outros campos científicos, como a Sociologia Política ou a Filosofia Política.

A segunda seção do artigo, por outro lado, se propõe a tarefa mais complexa e desafiadora: sintetizar a teoria da sociedade de Pierre Bourdieu em algumas poucas páginas. Trata-se de ousadia enorme e, certamente, seria criticada pelos especialistas na obra do sociólogo francês, em face da extraordinária riqueza analítica de um autor 
de enorme produção científica. No entanto, o objetivo principal desta seção é, principalmente, destacar que Bourdieu também teve como objetivo central em seu "plano de vôo sociológico" entender o fenômeno das hierarquias sociais e da "disposição dos agentes" nos diversos campos que organizam as relações entre os indivíduos. Dessa forma, a categoria poder ocupou a posição principal em sua teoria da sociedade. Ou seja, esta seção não tem a pretensão de ser capaz de sintetizar completamente uma teoria tão rica conceitualmente, como a de Bourdieu, mas enfatizar a centralidade da categoria poder em sua teoria e, assim, identificar mais claramente as diferenças entre os dois autores.

Finalmente, antes da curta seção conclusiva deste artigo, a terceira seção comenta criticamente os dois autores, mas dedicando-se, em especial, ao uso analítico do termo poder em ambos os casos e confrontando suas possibilidades de interpretação dos processos sociais. Insistir-se-á que, não obstante a instigante proposição de Lukes e os avanços analíticos que sua teorização sobre o assunto permitiu, a teoria da sociedade de Boudieu é mais promissora, em particular por situar "poder" no âmbito de uma teoria da sociedade. Em outras palavras, o principal foco desta terceira seção será argumentar que um conceito de poder é crucialmente necessário. Entretanto, se apresentado isoladamente, como Lukes propôs, a compreensão sobre as hierarquias sociais (e o fenômeno do poder e da dominação, em geral) é apenas parcialmente alcançado ${ }^{2}$. Articulado, no entanto, a uma teoria da sociedade, como é o caso da teoria de Bourdieu, ampliam-se as chances de interpretação sociológica e de compreensão de tais fenômenos.

\footnotetext{
${ }^{2}$ Embora conceitos weberianos próximos à categoria de "poder", este texto não discutirá termos como dominação, disciplina ou autoridade. Este último tem uma longa discussão igualmente tornada clássica por Weber (os tipos-ideais de autoridade), enquanto os primeiros termos foram entendidos pelo célebre autor alemão segundo "[...] dominação denominar-se-á a probabilidade de encontrar obediência a uma ordem de determinado conteúdo em dadas pessoas; disciplina chamar-se-á a probabilidade de, numa multidão dada de homens, encontrar uma obediência pronta, automática e esquemática a uma ordem, em virtude de uma atitude adestrada" (WEBER, 2012, p. 85).
} 


\section{2 “Power: a radical view” (1974; 2005) - a categoria 'poder' em Lukes ${ }^{3}$}

Até o lançamento de seu livro, na década de 1970, o debate em torno do poder, na Ciência Política, girou em torno de duas grandes posições, especialmente debatidas pela Ciência Política norte-americana. De um lado, a posição minoritária do weberiano Wright Mills, a partir de seu livro "A elite do poder", lançado em 1956 e centrado na discussão do poder amealhado pelas "elites", um conceito que, naquele livro, é mal definido, pois bastante vago. A posição oposta, e na época amplamente dominante nas Ciências Sociais daquele país, era decorrente da visão pluralista das teorias democráticas então vigentes e simbolizada na obra de Robert Dahl, lançada em 1961 "Who Governs? Democracy and Power in an American City".

O pequeno livro de Steven Lukes se insurgiu ante esta dicotomia, tendo sido influenciado também pelo Marxismo, ainda que este autor jamais tenha sido um cientista social marxista. O autor intitulou sua contribuição teórica de "as três dimensões do poder", todas relevantes de serem conhecidas, mas, quando isoladas, o fenômeno da distribuição e apropriação do poder se tornaria incompleto. A primeira dimensão diz respeito ao "estudo do comportamento concreto e observável" entre atores sociais envolvidos em processos de decisão política (LUKES, 2005, p. 17) e seria associado à perspectiva analítica de Dahl, conforme o livro citado acima. Sob tal ângulo, o que seria relevante seria a percepção acerca de manifestações de poder decorrentes de conflitos observáveis entre interesses organizados e sobre temas políticos concretos (DAHL, 1961). O poder, alegou aquele autor norte-americano, está mais visivelmente à mostra e em funcionamento quando existe um conflito de interesses entre os agentes sociais (sejam eles individuais ou coletivos), e um prevalece sobre o outro. É o que se chama de "poder [de A] sobre [B]" - ou "power over", na conhecida expressão da literatura em inglês". Ao exercer o poder, o agente mais poderoso demonstra que detém o poder, mas como o poder é, sobretudo, uma capacidade, aquele agente pode deter o poder

\footnotetext{
${ }^{3}$ Nascido na Inglaterra, Steven Lukes escreveu amplamente em torno de temas relativos à "política", seja pelo ângulo da Sociologia, da Ciência Política ou da Filosofia Política. Seus livros sobre Durkheim são referenciais, mas foram seus estudos sobre a categoria poder que o alçaram à posição de imensa respeitabilidade nas Ciências Sociais. É atualmente professor na Universidade de Nova York. Ver outras informações em sua página pessoal na internet: http://stevenlukes.net.
} 
sem exercitá-lo necessariamente. Sob esta dimensão, portanto, o conflito é entre claras preferências dos agentes, ao ser revelada uma das escolhas decisórias de um dos agentes (o mais poderoso). Pode ocorrer sob forma interpessoal, entre grupos ou até mesmo entre nações e seus conflitos (e, sem dúvida, aquele exercício de poder pode ser legítimo ou não). No estudo de Dahl, o grupo de pesquisadores testou a hipótese de estar o poder concentrado nas mãos de um grupo dirigente (a elite), mas concluíram que não existiria uma "elite de poder" (a tese de Mills), pois o poder estava distribuído "pluralisticamente" entre diferentes grupos sociais.

Seria este primeiro foco, portanto, relevante, mas bastante limitado - apenas temas políticos sobre interesses divergentes e que fossem claramente percebidos empiricamente. Dessa forma, esta seria, de acordo com Lukes, a "primeira dimensão do poder". Ou seja, centrada em comportamentos sociais observáveis nas esferas de tomada de decisão, mas somente aquelas que fazem parte das estruturas formais, públicas e legítimas no jogo pluralista da política.

A segunda dimensão do poder foi identificada por Lukes em um artigo acadêmico de dois cientistas políticos norte-americanos que analisaram criticamente a visão de Dahl, logo após a publicação de seu livro (BACHRACH; BARATZ, 1962). Identificaram a falha da análise contida no livro de Dahl e propuseram uma "segunda face" das expressões de poder na vida em sociedade. Sua crítica mais saliente diz respeito às forças sociais que, ao comandarem poder, impedem que determinados temas façam parte da agenda política e, desta forma, o importante seria identificar as forças sociais "ocultas" que impedem a formação da agenda política de uma determinada sociedade ou comunidade política. Para Bachrach e Baratz, as manifestações de poder também estão em curso quando os mais poderosos podem, com maior ou menor intenção, suprimir ou afastar desafios aos seus interesses através do controle da agenda. Ou seja, quando são capazes de decidir o que deve ser decidido. Por exemplo, impedindo que certos itens assumam uma disputa pública e política, os quais poderiam representar interesses reais daqueles grupos sociais subordinados. E, se tal controle é feito com maestria, a agenda pública jamais afetará a estrutura de poder. Dizendo de outra forma: o poder, assim entendido é, sem dúvida, mais efetivo quando menos 
frequentes forem as contestações à agenda política existente em uma dada sociedade. Em síntese: o estudo do poder requer aprofundar a análise da agenda política, mas igualmente identificando os temas vetados por aqueles que detêm o poder e, em decorrência, os grupos sociais mais poderosos, capazes de impor a agenda e, na outra face, as coletividades sociais prejudicadas.

Em consequência, para Lukes faltaria uma "terceira dimensão do poder", a qual seria ideológica em sua natureza. Neste caso, argumentou que existem manifestações mais profundas e ocultas de poder na sociedade. De acordo com esta dimensão, o poder está em funcionamento sob várias formas e "escondido" da percepção daqueles a ele subjugados e, algumas vezes, oculto até para os seus detentores. Sob este terceiro foco, o poder não é apenas a habilidade de prevalecer sobre outros em conflitos de interesses, ou determinar a agenda de tais conflitos (que seriam as duas dimensões anteriores): o poder também engloba os demais no sentido de obter a sua dependência, aderência, aliança ou cumplicidade, mesmo não precisando ser exercido, quando não existe conflito. De acordo com o autor,

[...] não é o supremo e mais insidioso exercício do poder impedir as pessoas, seja em qual grau isto acontecer, de desenvolver reivindicações em função de conformar suas percepções e preferências de tal forma que aceitam o seu papel na ordem existente das coisas, seja porque não podem ver ou imaginar nenhuma alternativa a ela, ou então porque veem-na como natural e imutável, ou ainda porque a valorizam como organizada por um benéfico poder divino? (LUKES, 2005, p. 28).

Essa terceira dimensão do poder seria associada à noção de alienação ou "falsa consciência" proposta pela tradição marxista, claramente expressa, sobretudo, nos escritos do chamado "jovem Marx" (sobretudo em seu livro "A ideologia alemã"). Posteriormente, uma categoria de efeitos práticos similares proposta por Gramsci deixaria ainda mais evidente essa proximidade entre a terceira dimensão proposta por Lukes e o Marxismo - a categoria de hegemonia. Embora Lukes tenha citado Gramsci, não discute longamente o autor italiano, não obstante a sua terceira dimensão de poder ser nitidamente associada à categoria proposta pelo fundador do $\mathrm{PCl}$ em seus diversos escritos sobre a construção de uma hegemonia popular, socialista e democrática em sociedades capitalistas ocidentais. Gramsci escreveu que seria corriqueiro, em 
determinado grupo ou classe social que experimenta uma situação de subordinação com relação a outro grupo, adotar a concepção de mundo deste último, mesmo que em contradição com a sua atividade prática. Dessa adoção acrítica de uma concepção de mundo de outro grupo social (o que deteria mais poder), resultaria um contraste entre o pensar e o agir, entre a coexistência de duas visões de ver e interpretar a sociedade. (ver, mais detalhadamente, o estudo sobre o pensamento de Gramsci em COUTINHO, 1992).

Dessa forma, a terceira dimensão do poder rejeita dois focos presentes na literatura. Primeiramente, o exercício e as manifestações de poder raramente (se alguma delas assim ocorrer) podem ser "positivas", ainda que os subordinados aceitem passivamente sua posição subalterna. Estes podem antecipar os poderosos e usar de autocensura, podem mostrar deferência, aceitando a desigual posição como "natural" e, assim, demonstrar uma aparente passividade frente a uma situação ostensiva de poder que indica conflito de interesses. A terceira dimensão do poder, se analisada corretamente, demonstraria exatamente essa desigual apropriação de poder e o desenvolvimento de uma "hegemonia" do grupo mais poderoso sobre os demais, inclusive no plano cultural. Outro foco que esta terceira dimensão rejeita é que o poder se manifesta apenas quando existe conflito de interesses, não sendo assim porque, muitas vezes, a mais eficaz manifestação de poder é exatamente a capacidade de evitar conflitos. Novamente, se estudada com rigor, a terceira dimensão poderia evidenciar a repressão à manifestação de interesses.

Em síntese, as três dimensões analisadas por Lukes poderiam ser esquematizadas como podem ser vistas a seguir:

O poder unidimensional: o foco é dirigido a comportamentos sociais dos agentes; processos decisórios são o espaço do poder; apenas os temas principais e chave na agenda política; conflitos abertos e observáveis; interesses sociais entendidos como preferências nas políticas e revelados através da participação dos atores.

Visão bidimensional do poder: processos decisórios permitem o controle da agenda política (e não necessariamente através de decisões transparentes); temas principais, mas também aqueles potenciais; conflitos observáveis, mas também aqueles 
ocultos; interesses sociais vistos como preferências de políticas, mas também reivindicações.

A visão tridimensional do poder proposta por Lukes: trata-se de uma crítica ao enfoque comportamental, e o foco é dirigido aos processos decisórios e o controle sobre a agenda política (nem sempre passando por decisões transparentes); temas principais e também os potenciais; conflitos abertos, potenciais e latentes; interesses subjetivos e reais.

$\mathrm{Na}$ segunda edição do livro (LUKES, 2005), em um capítulo especialmente dedicado a analisar a repercussão do livro original e as críticas recebidas, o autor indica que talvez o maior problema empírico para estudar o poder e suas expressões concretas seja exatamente o resultado de sua "terceira dimensão", acima indicada. A questão seria a seguinte: Como se poderá saber se, na ausência de "conflitos observáveis", a aceitação e a obediência (às formas de poder), aparentes ou não, tenham sido socialmente construídas a partir de um poder (do controle da informação e da formação de consciências coletivas) que tem a possibilidade de estruturar o imaginário social e as formas de pensar dos grupos sociais dominados por aquele poder, conformando suas crenças? Em particular, como será possível afirmar, empiricamente, que o consenso social existente não é aparente, mas resulta do "poder de manipular e enganar", levando as pessoas a apoiarem seus líderes ou políticas que, de fato, mantêm a estrutura desigual de poder e a subalternidade?

Lukes não oferece respostas convincentes a este desafio empírico, embora alguns estudos de seus seguidores nas Ciências Sociais tenham feito grandes esforços metodológicos para analisar as formas e expressões de poder em situações concretas. Um desses autores tem sido John Gaventa, um sociólogo norte-americano, atualmente radicado no Canadá. Primeiramente, em sua tese de doutoramento, analisou as comunidades pobres das regiões de mineração dos Montes Apalaches, nos Estados Unidos (sobretudo no estado da Carolina do Norte, estendendo-se mais ao Sul, até o Alabama), demonstrando a forma como as companhias de mineração foram hábeis na manipulação da informação e na constituição de visões de mundo que, durante décadas, formaram 0 imaginário coletivo das famílias moradoras daquelas 
comunidades (GAVENTA, 2006). ${ }^{4}$ Mais recentemente, o mesmo autor tem feito esforços analíticos ainda mais significativos para oferecer um caminho metodológico para perceber as formas de poder em uma dada situação social. Para isso, vem propondo a "teoria do cubo do poder", a partir da qual o poder pode ser entendido de uma forma tridimensional, seguindo Lukes. A Figura 1, na próxima página, sintetiza o "cubo do poder" proposto por Gaventa:

Figura 1. A proposta visual da "teoria do cubo de poder"

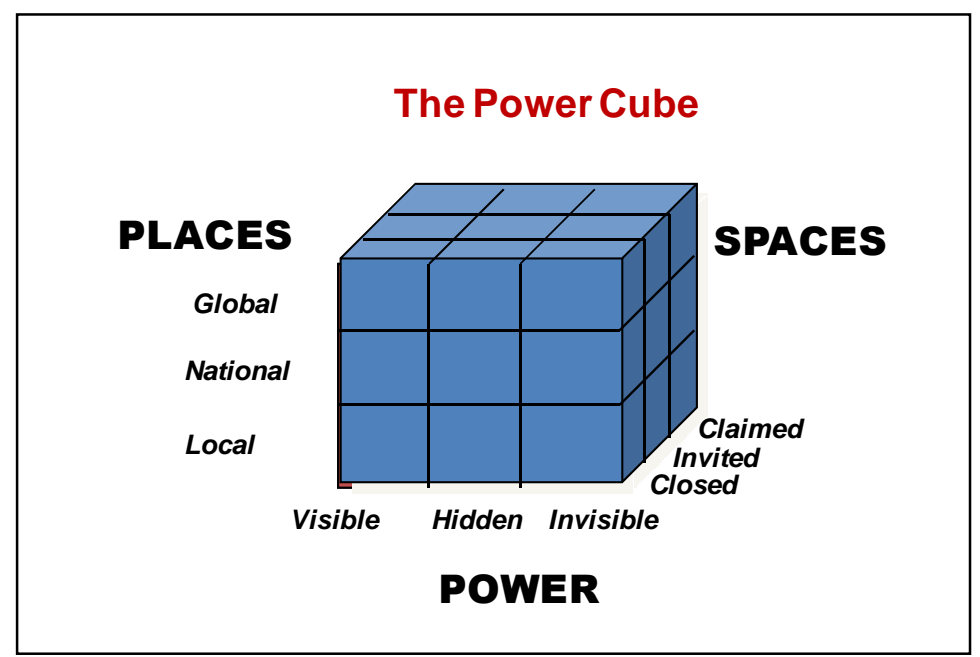

Fonte: Gaventa (2006).

Importante reafirmar que Gaventa inspirou-se largamente na proposta original de Lukes e, mais recentemente, desenvolveu esforços no sentido de ampliar ainda mais a visão tridimensional pioneira, desenvolvendo, portanto, o "cubo do poder", mas as três dimensões são apenas aquelas da face frontal do cubo (as formas de poder visíveis, ocultas e invisíveis), enquanto as demais dimensões se referem aos "lugares de origem" do poder: à esquerda (locais, nacionais e globais), e, no lado direito, os "espaços de poder" (fechados, abertos e reivindicados), estes últimos relacionados à ação política dos agentes sociais, em diferentes situações concretas (ver Gaventa, 2006).

\footnotetext{
${ }^{4}$ É possível encontrar uma discussão mais extensa sobre a "teoria do cubo do poder", inclusive documentos bibliográficos em http://www.powercube.net/analyse-power/what-is-the-powercube/.
} 


\section{A categoria 'poder' na teoria sociológica de Bourdieu ${ }^{5}$}

Inicialmente, é preciso insistir que é impossível resumir em poucas páginas a obra de Pierre Bourdieu, mesmo se for restrito ao mais essencial. Ocupando a posição de uns dos maiores sociólogos de todos os tempos, sua produção foi vastíssima. Pierre Bourdieu talvez tenha sido o último dos grandes sociólogos cujo legado possa ser identificado como uma "teoria da sociedade". Ao organizar um dos primeiros livros de autores brasileiros que analisaram a contribuição de Bourdieu, Ortiz (1983, p. 7) salientava não ser Bourdieu um "autor clássico", ao apresentar a coletânea de excertos contidos em seu livro, que foi pioneiro ao introduzir o autor francês. Provavelmente era avaliação apropriada em 1983, quando veio a lume aquele volume. Trinta anos depois, contudo, Bourdieu dificilmente deixaria de ser incluído entre os maiores e mais clássicos autores da Sociologia, o autor de uma Sociologia criativa, original e de excepcional solidez conceitual.

Nascido de uma modesta família de classe média baixa, no sudeste rural da França, sua produção é impressionante: escreveu sobre cultura e as classes sociais; sociologia da linguagem; sobre comunidades camponesas e grupos sociais na Argélia; educação; gostos culturais e dos consumidores; religião e ciência na França moderna, e até mesmo sobre os aspectos sociais dos mercados de habitação franceses ou sobre os artistas e escritores do Século XIX. Seu modelo teórico segue uma rígida lógica de consistência interna e evolução interpretativa, começando com seus trabalhos na Argélia, onde conduziu estudos etnográficos entre as comunidades Kabylia, o que o levou a publicar seu primeiro livro em 1958 ("A Sociologia da Argélia”).

Seu projeto teórico foi também um ambicioso esforço para confrontar alguns dos antigos dilemas das Ciências Sociais. O propósito principal foi criar uma teoria das práticas sociais e da ação humana que se distanciasse da persistente polarização entre

\footnotetext{
${ }^{5}$ Falecido em 2002, a produção científica de Pierre Bourdieu cobre aproximadamente 45 anos de trabalho contínuo. Escreveu pouco mais de trinta livros (muitos em colaboração). Uma lista completa dos trabalhos de Bourdieu pode ser localizada no link citado ao final. Saliente-se também que a elaboração desta seção contou com a orientação do sociólogo Zander Navarro, pesquisador da Embrapa. Seu artigo recente sobre a obra do autor francês (NAVARRO, 2006) foi essencial para compreender a obra de Bourdieu. Para uma consulta às obras completas de Pierre Bourdieu, existem diversas possibilidades, e sugere-se o link: http://hyperbourdieu.jku.at/start1.htm.
} 
"ação social e estrutura", mas também tentou afastar-se analiticamente das disputas epistemológicas entre subjetivismo e objetivismo. Se o primeiro engloba formas de conhecimento centradas na consciência individual ou intersubjetiva, o objetivismo se referiria aos produtos do conhecimento que focam as regularidades estatísticas da conduta social. A teoria geral da sociedade de Boudieu, assim como alguns de seus mais importantes conceitos, como habitus e campo, transcendem a tais polaridades.

A Sociologia de Bourdieu reflete uma influência bastante eclética, derivada da chamada "Sociologia clássica". Absorveu diversos ensinamentos de Durkheim, Marx e, em particular, de Max Weber. Em Marx, inspirou-se na idéia da reprodução social, e sua teoria incorpora facetas do materialismo histórico e também do argumento de que os conflitos de classe e os interesses materiais são os pilares principais da desigualdade social. Embora um materialista, quando relaciona a consciência humana à vida material, Bordieu rejeita, contudo, o reducionismo de classe, que é corriqueiro nas narrativas marxistas convencionais. Conferiu grande importância à idéia de falsa consciência, embora a chamando de "não reconhecimento" - por exemplo, quando estudou as relações de poder e explicou por que os indivíduos não estão conscientes de sua subordinação aos agentes mais poderosos da sociedade. Também incorporou, em seus escritos, a idéia marxista sobre os sistemas simbólicos que reforçam os sistemas de dominação, embora rejeitando que esses seriam o resultado direto de dimensões materiais, sobretudo a apropriação desigual da riqueza. Em consequência, Bourdieu acabaria recusando a oposição de causalidade postulada pelo Marxismo entre infraestrutura e superestrutura.

Em sua teoria, o mundo social pode ser interpretado como sendo constituído por uma série de campos relativamente autônomos de produção, circulação e consumo, mas estruturalmente homólogos e concretizados sob as mais variadas formas culturais, assim como também formas materiais e uso de recursos diversos. Em consequência, Bourdieu procura propor uma teoria geral de práticas sociais que combina ambas, as dimensões materiais e as simbólicas, assim enfatizando a unidade fundamental da vida social. Em sua visão, é incorreto indicar, antes da necessária verificação empírica, as hierarquias estruturais entre os campos da ação social em uma dada sociedade 
concreta - ou seja - a predominância da economia, por exemplo. Segundo seu esquema analítico, apenas as circunstâncias específicas, depois de pesquisadas, é que irão demonstrar aquelas relações e as hierarquias existentes em uma dada situação.

Contudo, foi Weber que talvez tenha sido o autor clássico mais influente na obra de Bourdieu. Como o pensador alemão, o autor se pergunta: "O que motiva a ação social? Os indivíduos agem em resposta a causas externas, como 'cultura' ou 'estruturas sociais', ou somente agem em função de suas próprias e identificáveis razões?". Weber optou pela segunda parte da pergunta, quando analisou o comportamento religioso dos indivíduos. Bourdieu, contudo, foi mais além e com maior ousadia - para o autor francês, todas as ações sociais, em todas as esferas da interação humana, respondem precipuamente a interesses. Mesmo as ações aparentemente "desprendidas" e apresentadas generosamente como sendo "desinteressadas", responderiam igualmente a interesses, no geral, inconfessáveis. Propôs uma ciência das práticas sociais que tem como pressuposto (não uma hipótese) que todas as práticas sociais são orientadas à maximização dos interesses materiais ou dos resultados simbólicos, ou seja, são auto-motivadas. Interesses materiais ou simbólicos são formas objetivas de interesse individual, e foi aquele pressuposto que, por exemplo, permitiu a Bourdieu desenvolver o capital religioso ou cultural como uma "forma de poder". Essas formas de capital podem ser produzidas sob diferentes estratégias e comando de recursos, acumulados ou trocados com outras formas de capital, incluindo o capital econômico. São recursos transformados em capital, quando funcionam como relações de poder, no âmbito de uma estrutura de hierarquias sociais. Dessa forma, tornam-se objeto de conflitos e disputas, de lutas e antagonismos.

A teoria de Bourdieu parte de dois princípios genéticos e fundamentais sobre o comportamento humano, ambos sintetizados em uma curta frase do autor: "Posso dizer que todo o meu pensamento começou com o seguinte aspecto: como pode o comportamento social ser regulado sem ser o produto da obediência às regras?" (BOURDIEU, 1990, p. 65). Primeiramente, e ecoando o escrito acima, o autor argumenta que todas as ações sociais, em todos os arranjos societários, são motivadas por interesses, independentemente das especificidades desses arranjos. Como as 
práticas sociais demonstram regularidade além das regras formais e escritas, como explicá-las?

Desta forma, Bourdieu mantém que, sendo o autointeresse a força motora das práticas sociais, o resultado é que as lutas sociais (e, portanto, as disputas por poder) são a principal faceta dos arranjos sociais em qualquer campo, porque os indivíduos tentam maximizar seus ganhos e acumular recursos sob diferentes formas de capital (recursos e capitais econômicos, sociais, culturais, simbólicos). O resultado histórico de tais esforços, contínuos e persistentes, de acumular recursos é materializar hiearquias e desiguais distribuições de poder, as quais exigem uma vigilância permanente para legitimar essas diferenças. Assim se explicam, portanto, os esforços para manter o "não reconhecimento" sobre as origens de tais assimetrias sociais. Essa é a razão pela qual a teoria de Bourdieu é essencialmente política e enraíza, sobretudo, as relações de poder em seu centro analítico.

O segundo princípio fundador de sua teoria é a noção de que a cultura não é apenas o espaço primeiro da interação humana, mas é também um terreno especial de dominação. Bourdieu argumenta que todos os sistemas simbólicos estão ancorados na cultura, os quais determinam a nossa compreensão sobre a realidade. A cultura, na forma de disposições, objetos, instituições, linguagem, etc., é a forma principal da mediação de todas as práticas sociais, quando articula os indivíduos e grupos sociais às hierarquias institucionalizadas. $\mathrm{E}$, assim, também a cultura, necessariamente, embute, em suas manifestações, diversas relações de poder e as hierarquias existentes. Novamente, se assim não fosse, as práticas sociais não mostrariam regularidades fora das regras formais e instituídas.

Sempre que uma dada sociedade se desenvolve e cresce através de processos de expansão material e seus correlatos processos de diferenciação social (e, portanto, apresentam uma crescente complexidade), a cultura e os sistemas simbólicos podem se transformar em arenas de luta social, relativamente autônomas em relação aos demais campos. Essa possibilidade é sintetizada na palavra "disposição", que indica um conceito crucial na teoria de Bourdieu (BOURDIEU, 1984). Dessa forma, em dadas situações, o capital cultural pode ser de enorme valor para perpetuar as hierarquias e 
as diferenças sociais. Em seus estudos sobre a sociedade francesa, em especial os impactos do sistema educacional em garantir uma rígida distribuição de poder (e a permanência das desigualdades sociais), esse tipo de capital foi amplamente analisado e demonstrado por Bourdieu, alçando-o imediatamente à posição de um nome referencial na Sociologia da Educação.

Quais seriam os conceitos-chave na arquitetura teórica de Bourdieu? São inúmeros, sendo ele um autor erudito e com ampla formação multidisciplinar, incluindo um sólido conhecimento em Filosofia. Por ser este um artigo curto, talvez a única forma razoável de introduzir o arcabouço teórico do autor, além das considerações acima, seja o ponto de partida sugerido em um de seus livros mais famosos, "Distinções" (BOURDIEU, 1984, p. 101). No livro, o autor oferece uma equação que aponta os seus conceitos principais e, também, a relação entre eles, como se apresenta a seguir:

\section{[(Habitus) $\times$ (capital) $]+$ campos = práticas sociais}

Habitus é o conceito central na obra de Bourdieu e evoluiu a partir de seus estudos realizados na Argélia, a partir do final dos anos cinquenta. É conceito que tem raízes aristotélicas, mas, para Bourdieu, indica não apenas a base fundadora das práticas sociais, mas é também um recurso conceitual que permite evitar os impasses desenvolvidos pelas Ciências Sociais entre a ênfase objetivista e o outro polo subjetivista. Sua definição pode ser entendida a partir da referência abaixo, oferecida por um dos maiores especialistas na obra de Bourdieu. Para este autor, habitus é:

[...] uma noção mediadora que revoga a dualidade do senso comum entre o indivíduo e o social ao capturar a 'internalização da externalidade e a externalização da internalidade' [na famosa expressão de Bourdieu], ou seja, é o caminho sob o qual a sociedade se torna depositada nas pessoas na forma de disposições duradouras, ou capacidades treinadas e propensões estruturadas para pensar, sentir e agir sob determinadas formas, as quais guiam os indivíduos em suas respostas criativas aos constrangimentos e solicitações do seu meio (...) [habitus] é constituído de uma inércia de fabricação, pois habitus tende a produzir práticas padronizadas pelas estruturas sociais que as ampliam, e também porque cada uma de suas camadas operam sob um prisma, através do qual as experiências últimas são filtradas e os subsequentes estratos de disposições são depositados (por isto, o desproporcional peso dos esquemas implantados na infância) (WACQUANT, 2005, p. 316-317, grifos do autor). 
Em decorrência, através do habitus, as práticas sociais não são nem a imposição mecânica das estruturas nem o resultado de uma busca intencional "inteiramente livre" dos indivíduos. Não é uma faceta natural ou meramente individual, mas uma característica social, portanto variável através do tempo, lugares ou entre diferentes distribuições de poder em diferentes campos. É também transferível a distintas esferas de práticas sociais, o que explica a sua consistência empírica, quando analisado um determinado campo. Mas não é fixo ou permanente ou imutável e, certamente, modifica-se com o tempo histórico. Habitus se desenvolve, em especial, através dos processos de socialização e determina uma ampla gama de disposições que são formadas, estocadas, registradas e exercem influência na moldagem das formas de comportamento humano. Variará de acordo com o ambiente social, porque arranjos societários instáveis produzirão sistemas igualmente instáveis de disposições, que geram padrões irregulares de ação e de poder. Habitus reforça a coesão social, mas também estimula a mudança social, sobretudo quando não se articula adequadamente ao mundo social em que se desenvolve.

Se é uma condição necessária, não é, contudo, suficiente, quando se busca interpretar as práticas sociais. Capital (ou as formas de capital) é a segunda parte da equação. Sua essência é sugerir que todas as formas de recursos "que têm valor" (e, portanto, objetos de disputa conflituosa entre os agentes e, assim, os ingredientes fundantes das hierarquias de poder) sejam recursos simbólicos, materiais, culturais ou sociais. Para Bourdieu, os recursos funcionam como capital quando estabelecem "uma relação de poder", porque tal fato é que atribui valor aos recursos, a partir do interesse dos indivíduos em apropriá-los e acumulá-los. É também relevante salientar que, para o autor francês, nenhum dos recursos acumulados é a priori dominante, o que representa uma clara ruptura com a teoria marxista (que enfatizaria a primazia dos recursos econômicos sobre os demais). Ou seja, os indivíduos mobilizam os recursos para manter sua posição (disposições) em um dado campo, e esses recursos são formas de capital quando funcionam como relações de poder - em outras palavras - quando são objetos de lutas sociais. Bourdieu normalmente menciona quatro tipos de capital: econômico (dinheiro e propriedade), o capital cultural (bens culturais e serviços, 
também incluindo as credenciais educacionais), o capital social (redes e conhecimentos pessoais) e o capital simbólico (o qual se refere à legitimidade de uma dada situação de poder).

O terceiro conceito central, para Bourdieu, é campo. É conceito que Bourdieu passou a discutir mais extensamente durante a década de 1980, o que introduziu grande complexidade à sua obra. Um campo delimita a estrutura e o "território" onde o habitus opera. O autor propôs uma definição para campo, como sendo:

[...] uma rede, ou configuração, de relações objetivas entre posições. Essas posições são objetivamente definidas em sua existência e nas determinações que impõem sobre seus ocupantes, agentes ou instituições, através de sua situação presente ou potencial na estrutura da distribuição das espécies de poder (ou capital), cuja posse comanda acesso aos lucros específicos que estão à disposição no campo, assim como sua relação objetiva com outras posições (WACQUANT; BOURDIEU, 1992, p. 97).

"Campos", portanto, no âmbito da teoria cultural do poder de Bourdieu, representam conceitos que interpretam uma certa estrutura de distribuição de alguns tipos de capital e indicam "arenas de lutas sociais" em torno da produção, acumulação, circulação e posse de bens, serviços, conhecimento, status e a decorrente competição entre os agentes para monopolizar distintos capitais. Podem ser pensados como espaços estruturados que são organizados em torno de capitais específicos ou combinações de capital. Bourdieu propõe o estudo de diversos campos, como o intelectual, o religioso, o educacional, o cultural e diversos outros. A sociedade seria formada de inúmeros campos onde os agentes atuam mais (ou menos) intensamente, e todos eles indicam hierarquias e disputas - ou seja - os campos são espaços de poder. Dessa forma, conceito de campo remeteria a um:

[...] espaço onde as posições dos agentes se encontram a priori fixadas [pela citadas 'disposições duráveis']. O campo se define como o locus onde se trava uma luta concorrencial entre os atores em torno de interesses específicos que caracterizam a área em questão (...) resolve-se o problema da adequação entre ação subjetiva e objetividade da sociedade, uma vez que todo ator age no interior de um campo socialmente predeterminado. A prática, conjunção de habitus e da situação, ocorre desta forma no seio de um espaço que transcende as relações entre os atores. Toda a eficácia da ação se encontra assim prefigurada, o que implica dizer que 0 ator só realiza aquelas ações que ele pode realmente efetivar (ORTIZ, 1983, p. 19). 
Não obstante as inúmeras dificuldades metodológicas para aplicar a teoria proposta por Bourdieu (assim gerando as infindáveis controvérsias em torno de sua obra), o que o autor francês propôs é essencialmente um caminho para descobrir os mecanismos ocultos de poder, o que permitiria identificar as formas de dominação, as hierarquias sociais existentes e seus sustentáculos, a acumulação de recursos em mãos de certos agentes, assim como a desmistificação de formas de justificação ideológica. Neste ponto, portanto, a teoria de Bourdieu se aproxima da terceira dimensão de poder proposta por Lukes. Cabe, portanto, um comentário comparativo, ainda que sucinto, sobre os dois autores e suas interpretações acerca do poder na sociedade humana.

\section{Um breve comentário crítico comparativo}

"Poder" tem sido uma das categorias mais discutidas e controversas no pensamento social. Um dos especialistas que estudou tal conceito indicou graficamente as possibilidades analíticas, segundo diversas perspectivas teóricas, conforme a Figura 2 (abaixo). A representação de relações entre os autores e suas características não demonstra claramente as mais influentes correntes teóricas sobre o poder. Uma visão extremamente influente, não discutida neste artigo, é aquela proposta por Foucault (intitulada de "pós-moderna" na figura). Ainda assim, deve ser ressaltado que os arcabouços teóricos, indicados na figura, derivados das contribuições, de Lukes e de Bourdieu, continuam sendo igualmente influentes.

Comparativamente, portanto, aqui reside um aspecto positivo dos dois enfoques, que têm tido cientistas sociais seguidores que vêm tentando desenvolver caminhos metodológicos que permitam evidenciar empiricamente as formas de poder e suas relações em distintos contextos, ao contrário das correntes foucaultianas, para as quais "o poder é tudo", o que dificulta fortemente os estudos propriamente empíricos, relegando a importante contribuição do filósofo francês a estudos mais especulativos do que propriamente analíticos por parte de seus seguidores. Diferentes e variados esforços de numerosos autores, inspirados em Lukes e Bourdieu, pelo contrário, 
procuraram adaptar as contribuições conceituais e teóricas dos dois autores em "caminhos metodológicos" que permitissem analisar concretamente, em diferentes contextos e situações, as manifestações de poder e suas características.

Figura 1 - O mapa conceitual da categoria "poder"

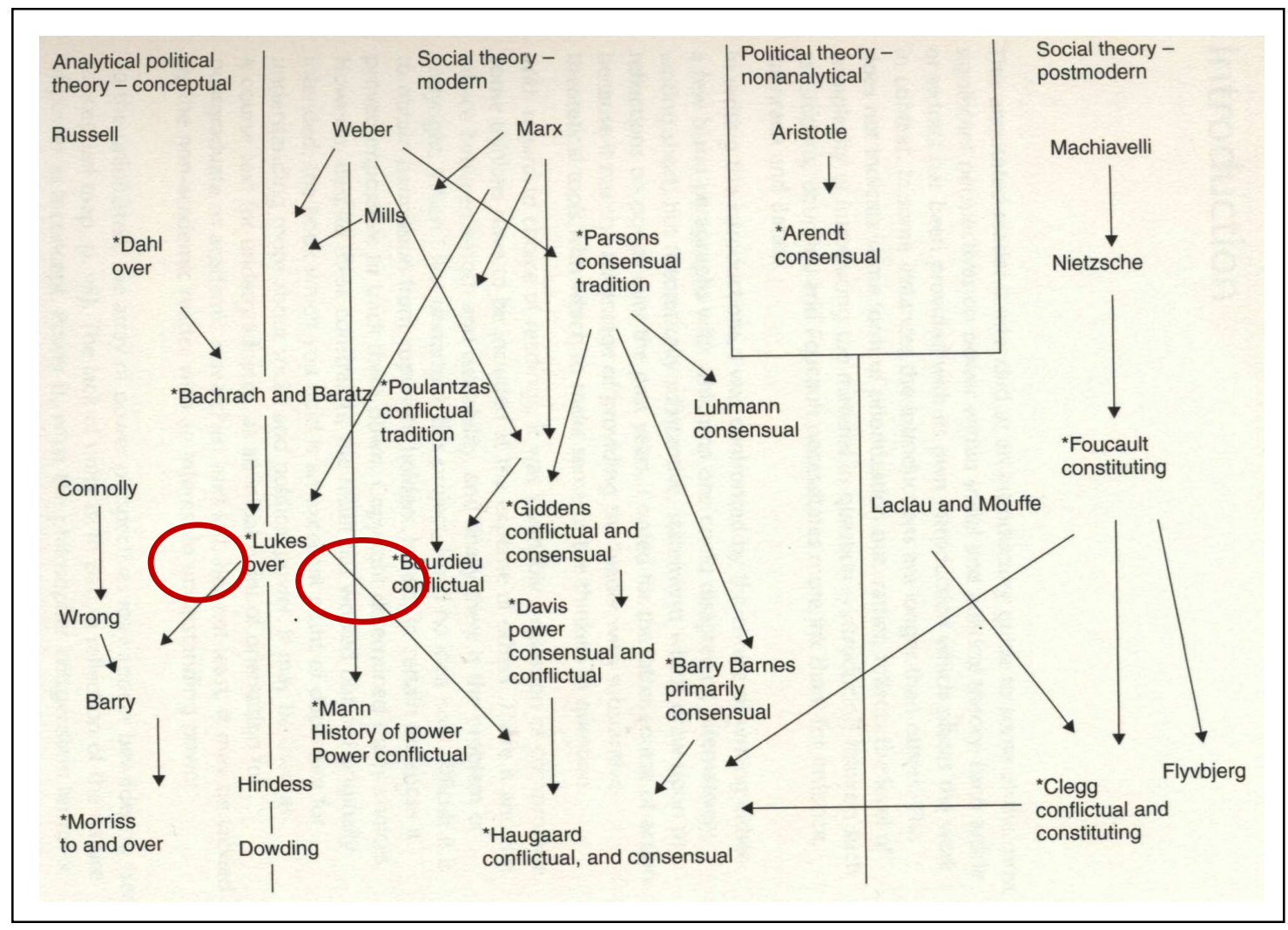

Fonte: Haugaard (2002).

No entanto, se a análise comparativa se restringe aos dois autores apenas, é possível desenvolver duas vias de comparação. Primeiramente, estudar individualmente cada um dos autores e suas contribuições e analisá-las em si mesmas, seja no tocante às suas virtudes conceituais e às inovações teóricas que propuseram, seja quanto às suas falhas e inconsistências, identificadas ao estudá-las mais aprofundadamente. Ou seja, tomar o conceito "radical" de poder submetido por Lukes e "abri-lo" detalhadamente, para identificar seus aspectos mais positivos ou suas falhas 
conceituais. O mesmo seria feito com a teoria cultural do poder de Bourdieu, embora, neste caso, uma ambição infinitamente mais ousada e passível de controvérsias.

Afirmado mais claramente, esta primeira estratégia comparativa indicaria um resultado que parece preliminarmente evidente: sempre será possível analisar mais detidamente um conceito, neste caso o conceito de poder proposto por Lukes e, pelo contrário, será praticamente impossível, pelo menos no escopo deste artigo, analisar aprofundadamente a teoria geral das práticas sociais de Bourdieu, pois o primeiro submeteu um conceito novo, enquanto o segundo uma "teoria da sociedade". Por essa razão, a literatura contém claramente as críticas a Lukes e sua perspectiva sobre o poder, enquanto a bibliografia sobre a "Sociologia de Bourdieu" é vastíssima e marcada por variações apreciativas, que se estendem da crítica mais ácida às visões apologéticas, no outro extremo. E, como "poder" ocupa uma posição heurística central na teoria geral das práticas sociais de Bourdieu, seria até equivocado separá-la, isolála, e tentar analisá-la por si só, o que de antemão configuraria um erro analítico. Em face desta abissal diferença entre o locus de poder apontado por Lukes - um mero conceito - e aquele defendido por Bourdieu (a categoria central em sua "teoria da sociedade"), torna-se impossível realizar uma comparação crítica ampla e completa em espaço tão curto de análise.

Por esta razão, esta sucinta seção final do artigo pretende apenas defender um argumento principal: Apreciar positivamente a contribuição de Lukes, por avançar substantivamente na compreensão sobre "poder" nas Ciências Sociais. Tal comparação estimulou inúmeros trabalhos de outros cientistas (especialmente na Ciência Política) que analisaram o conceito proposto por Lukes e aperfeiçoaram-no ainda mais, em diversos trabalhos subsequentes. Ou seja, as falhas lógicas da discussão sobre poder, em seu livro original de 1974, ainda que pudessem ter sido identificadas por alguns de seus leitores mais críticos, não tiram o brilho do pequeno livro e do fato de ter Lukes trazido à tona um conceito crucial para o entendimento dos arranjos societários.

A maior crítica ao conceito tridimensional de poder de Lukes, de fato, corresponde exatamente na vantagem aparente da teoria societária de Bourdieu e na óbvia diferença entre os dois autores - o primeiro oferece um conceito, e o segundo, 
uma "teoria da sociedade". Dessa forma, na visão oferecida por Lukes, faltariam elementos analíticos essenciais, que a mera definição de poder, se não for articulada a uma teoria da sociedade, será incapaz de desvendar. Por exemplo, diversas perguntas, entre diversas outras, imediatamente poderiam ser levantadas: quem tem poder, e como é possível identificá-los? O poder é capaz de existir em estruturas sociais e ser transformado em poder pessoal para conformar a ordem social e impelir os indivíduos a agirem seguindo determinadas trajetórias? Quais são os mecanismos que reforçam (ou reduzem) os mecanismos de poder? Quais são os resultados da distribuição de poder que realmente são relevantes? Pode o poder ser tão dissimulado, como sugeriu Lukes, que os indivíduos não percebem, de fato, linhagens de dominação e controle social que limitam sua autonomia e escopo para a ação? A passividade social é reflexo de padrões aprofundados de poder? A persuasão racional pode ser alcançada? Se o poder é tão crucial para interpretar um dado arranjo societário e, assim, identificar seus limites e possibilidades, em termos de ação social, como aferir empiricamente suas manifestações?

Sob o conceito de Lukes, as respostas a essas (e muitas outras) perguntas sobre a gênese, o desenvolvimento e a apropriação do poder em um dado contexto social poderão encontrar avanços explicativos substantivos, mas não serão respondidas na amplitude necessária. Apenas uma teoria da sociedade teria tal capacidade explicativa. Por isso, não obstante muitas controvérsias que cercam a teoria desenvolvida por Pierre Bourdieu, ela é um arcabouço teórico mais promissor para estudar o poder e suas manifestações do que o conceito original de Lukes.

\section{Conclusões}

Este artigo pretendeu oferecer uma comparação em torno da categoria "poder", talvez uma das mais centrais das Ciências Sociais, ainda que também um conceito altamente disputado em sua definição, de acordo com as diferentes perspectivas teóricas. Para tanto, foi sinteticamente apresentada a proposta original de Steven Lukes, de 1974, a qual estimulou amplo debate, especialmente na Ciência Política. 
A segunda seção do artigo, contudo, propôs uma síntese ainda mais ambiciosa embora praticamente impossível de ser realizada em espaço tão curto - uma apresentação sumariada da extraordinária Sociologia de Pierre Bourdieu, tentando localizar, em seu trabalho, a noção de poder e a construção de hierarquias sociais a partir das práticas sociais. Trata-se de ambição excessiva, em face da impressionante riqueza analítica que a contribuição do autor francês, desenvolvida em quase meio século de trabalho, legou à Sociologia.

Uma terceira seção do artigo, mais breve, apenas esquematiza as diferenças entre as duas contribuições em torno da ideia de poder. Argumenta-se, nesta parte, que o conceito de poder em Lukes, ainda que um avanço considerável em face dos estudos então existentes na década de 1970, é limitado em seu escopo interpretativo exatamente por se concentrar apenas na categoria em si mesma, mas deslocada de uma "teoria da sociedade". Dessa forma, Lukes se propõe a entender as formas de poder existentes em dada sociedade e suas manifestações concretas, mas não oferece um arcabouço teórico a partir do qual o poder pode ser entendido em suas origens e desenvolvimentos. Por fim, os temas das hierarquias sociais, da estrutura social e da desigualdade se tornam apenas parcialmente explicados. Em contrapartida, ao propor uma teoria da sociedade, a obra de Bourdieu permite preencher esta ambição analítica, sendo assim mais bem sucedida na tentativa de explicar a existência do poder em uma dada sociedade.

\section{Referências}

BACHRACH, P.; BARATZ, M. S. The two faces of power. In: American Political Science Review, 56, p. 941-952, 1962.

BÉLAND, D. Steven Lukes. Power: A Radical View. 2. ed. In: Canadian Journal of Sociology Online, jul./ago. 2006.

BOURDIEU, P. Distinction: A Social Critique of Judgement of Taste. Cambridge: Harvard University Press, 1984. The Logic of Practice. Stanford: Stanford University Press, 1990. 
COUTINHO, C. N. Gramsci. Um estudo sobre o seu pensamento político. Rio de Janeiro: Campus, 1992.

DAHL, R. Who Governs? Democracy and Power in an American City. New Haven: Yale University Press, 1961.

GAVENTA, J. Finding the spaces for change: a power analysis. In: IDS Bulletin, v. 37, n. 6, p. 23-32, 2006. Disponível em:

<http://www.forumsyd.org/upload/tmp/kapacitet/amnen_metoder/demokrati/PowerAnaly sis_John_Gaventa.pdf>. Acesso em: 20 maio 2013.

HAUGAARD, M. (Org.). Power. A Reader. Manchester: Manchester University Press, 2002.

HOBBES, T. Leviathan. Oxford: Clarendon Press, 1909. (Reimpressão do texto originalmente publicado em 1651).

LUKES, S. Power: A Radical View. Londres: Macmillan Press, 1974.

Power: A Radical View. 2. ed. Londres: Palgrave, 2005. (Versão original acrescida de dois capítulos inéditos).

MILANOVIC, B. Ter ou não ter. Uma breve história da desigualdade. Lisboa: Bertrand, 2012.

NAVARRO, Z. In search of a cultural interpretation of power: The contribution of Pierre Bourdieu. In: IDS Bulletin, v. 37, n. 6, p. 11-22, 2006.

ORTIZ, R. À procura de uma Sociologia da prática. In: BOURDIEU, Pierre. São Paulo: Ática, 1983. p. 5-36. (Coleção Grandes Cientistas Sociais, 39),

WACQUANT, L. Habitus. In: BECKERT, J.; ZAFIROVSKI, M. (Orgs.). International Encyclopedia of Economic Sociology. Londres: Routledge, 2005.

WACQUANT, L.; BOURDIEU, P. An Invitation to Reflexive Sociology. Chicago: Chicago University Press, 1992.

WEBER, M. Conceitos sociológicos fundamentais. Lisboa: Edições 70, 2012. 